\title{
Lattice corneal dystrophy type I
}

INSERM

\section{Source}

INSERM. (1999). Orphanet: an online rare disease and orphan drug data base. Lattice corneal dystrophy type I. ORPHA:98964

Type I lattice corneal dystrophy (LCDI) is a frequent form of stromal corneal dystrophy (see this term) characterized by a network of delicate interdigitating branching filamentous opacities within the cornea with progressive visual impairment and no systemic manifestations. 